\title{
Effect of Gas Permeation Temperature on Gamma-alumina Ceramic Membranes
}

\author{
Mohammed Nasir Kajama, Ngozi Claribelle Nwogu, Edward Gobina \\ Centre for Process Integration and Membrane Technology, (CPIMT), IDEAS Research Institute, School of Engineering, The \\ Robert Gordon University, Aberdeen, AB10 7GJ. United Kingdom.
}

\begin{abstract}
This paper examines gas permeation properties (feed pressure, temperature, molecular weight) using $\gamma$ alumina mesoporous ceramic membrane with $15 \mathrm{~nm}$ average pore size. Scanning electron microscopy (SEM) of the membrane's cross-sectional area was analyzed in this experiment. Single gas permeation of hydrogen, helium, methane, nitrogen, argon and carbon dioxide was determined at permeation temperature range of $25{ }^{\circ} \mathrm{C}-450{ }^{\circ} \mathrm{C}$ and feed pressure range 0.05 to $10 \mathrm{bar}$. It was shown that the transport mechanism under these conditions is governed by a combination of viscous and Knudsen diffusion.
\end{abstract}

Keywords-ceramic membranes; gas permeance; permeation temperature; gas molecular weight.

\section{INTRODUCTION}

Membrane gas separation is becoming the alternative technology in the chemical industry for purification processes because it requires minimum or no energy consumption [1, 2]. Membranes are barriers for gas separation from a feed gas mixture and produce permeate for other processes. Its performance can be dictated by the membrane strength, permeability and selectivity respectively. Membranes can be classified into organic and inorganic systems. The organic ones are further divided into biological and polymeric constituents, while the inorganic membranes can be divided into metallic and ceramic (porous and non-porous) membranes [3]. The International Union of Pure and Applied Chemistry (IUPAC) classified porous membranes as; Micropores $0.5-2 \mathrm{~nm}$, mesopores is $2-50 \mathrm{~nm}$ and macropores is $>50 \mathrm{~nm}[4,5]$. In recent time, membranes were fabricated from polymeric materials in the industry but these are limited to chemical attack and high temperature. It is for these reasons that inorganic membrane technology is receiving an ever increasing attention [6]. Inorganic membranes are commonly made from ceramic, metal oxide or sintered metal, palladium metal, zeolite among others [7].

Gas transport through inorganic membranes depend on pore size and pore size distribution, membrane materials as well as the chemical interaction between the diffusing gases [8]. The main transport mechanisms are viscous flow, Knudsen diffusion, surface diffusion and Solution-diffusion separation $[9,10,11]$.

The so-called Knudsen number is used to differentiate between viscous and Knudsen flow which is written as [12];

$$
K_{n}=\lambda / d_{p}
$$

Where; $\lambda$ is the mean free path of gas molecules, and $d_{p}$ is the pore diameter.

Basically, mean free path is the average distance travelled by the molecule between collisions. Therefore; mean free path is expressed as $[12,13]$;

$$
\lambda=\frac{R T}{\sqrt{2 \pi d^{2} N_{A} P}}
$$

Where; $\mathrm{R}$ is the gas constant $\left(8.314 \mathrm{~J} \cdot \mathrm{K}^{-1} \cdot \mathrm{mol}^{-1}\right), \mathrm{T}$ is the temperature $(\mathrm{K}), \mathrm{d}$ is the diameter $(\mathrm{m}), \mathrm{N}_{\mathrm{A}}$ is the Avogadro's number ( $\mathrm{mol})$, and $\mathrm{P}$ is the pressure $(\mathrm{Pa})$.

Viscous flow is determined if the mean free path is smaller than the pore diameter, the flow characteristics are determined primarily by collisions among the molecules and can be written as [12];

$$
P v=\frac{\varepsilon_{r 2(p 1+p 2) / 2 \Delta P}}{8 \pi \mu R T L}
$$

Where; $\mathrm{P}_{\mathrm{v}}$ is the viscous permeance $\left(\mathrm{mol} \mathrm{m}^{-2} \mathrm{~s}^{-1} \mathrm{~Pa}^{-1}\right), \varepsilon$ is the porosity of the membrane, $\mathrm{r}$ is the mean pore radius $(\mathrm{m}), \mathrm{p}_{1}+\mathrm{p}_{2} / 2$ is the average pressure $(\mathrm{Pa}), \Delta \mathrm{P}$ is the pressure difference $(\mathrm{Pa}), \mu$ is the viscosity (Pas), and $\mathrm{L}$ is the thickness of the membrane $(\mathrm{m})$.

Knudsen diffusion occurs if the mean free path is effectively larger than the pore diameter. The separation is based on molecular weight $[10,11,12]$. Thus, Knudsen permeance states that the permeation flux is proportional to the inverse square root of both molecular weights of gases and temperature which can subsequently be written as [12];

$$
P k n=\frac{\varepsilon 8 r \Delta P}{3 \tau L(2 \pi R T M) 1 / 2}
$$

Where; $\mathrm{P}_{\mathrm{kn}}$ is the Knudsen permeance $\left(\mathrm{mol} \mathrm{m}^{-2} \mathrm{~s}^{-1} \mathrm{~Pa}^{-1}\right)$, $\tau$ is the tortuosity and $\mathrm{M}$ is the molecular weight of the diffusing gas $(\mathrm{g} / \mathrm{mol})$.

However, if the mean free path of the gas molecules is equal to the pore diameter, then; the flow mechanism is governed by the combination of both mechanisms (i.e. Eq. 3 and 4) which is written as;

$$
P t=\frac{\varepsilon}{\tau L}\left[\frac{r 2(p 1+p 2) / 2 \Delta P}{8 \mu R T}+\frac{8 r \Delta P}{3(2 \pi R T M) 1 / 2}\right]
$$

Where $\mathrm{P}_{\mathrm{t}}$ is the total permeance $\left(\mathrm{mol} \mathrm{m} \mathrm{m}^{-2} \mathrm{~Pa}^{-1}\right)$.

Surface diffusion can occur in parallel with Knudsen diffusion. It occurs if the diffusing molecules adsorbed on the pore walls of the membrane and migrates along the pore surface. Solution-diffusion separation relies on the physicalchemical interaction of gases and the dense membrane that determine the amount of gas which accumulates in the membrane matrix [9].

In this study gas permeation behaviour from $\gamma$-alumina mesoporous ceramic membrane with $15 \mathrm{~nm}$ average pore 
size was studied at permeation temperature range of $25{ }^{\circ} \mathrm{C}$ $450{ }^{\circ} \mathrm{C}$ and feed pressure range 0.05 to 10 barg.

\section{EXPERIMENTAL}

This experiment was carried out with a $\gamma$-alumina mesoporous tubular ceramic membrane supplied by Ceramiques Techniques et Industrielles (CTI SA) France. It consists of $77 \% \alpha$-alumina and $23 \% \mathrm{TiO}_{2}$ with a nominal pore size of $15 \mathrm{~nm}$ and a porosity of $45 \%$. The membrane has a permeable length of $348 \mathrm{~mm}$ with I.D and O.D of 7 and $10 \mathrm{~mm}$ respectively. Fig. 1 shows a SEM image of the cross section of the membrane.

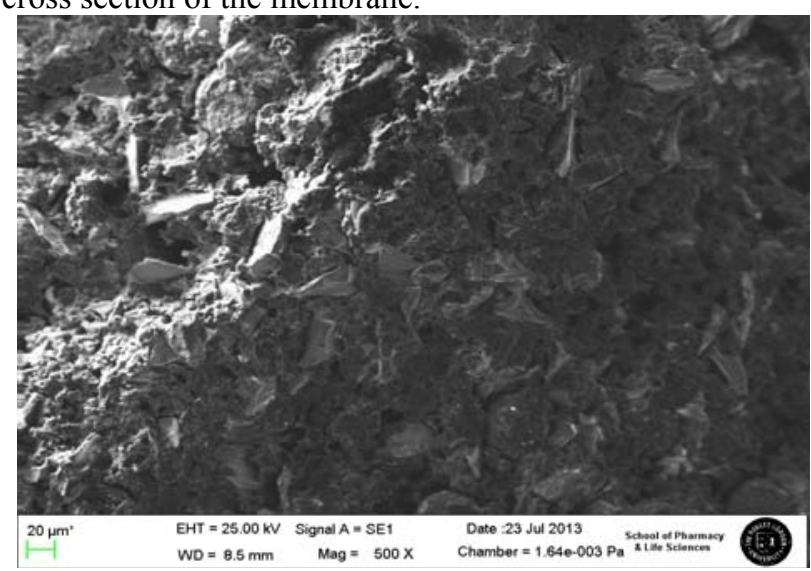

Figure 1. SEM image of the cross section of ceramic membrane

Table 1 summarizes the single gases used for the permeation test experiment. The gases were supplied by BOC UK. Gas permeance was measured under steady-state conditions using a tubular stainless steel membrane reactor with the retentate valve fully opened. The reactor is enclosed by a heating tape jacket Fig. 2, and the permeate flow tube was connected to the flowmeter to record gas flow rate.

TABLE I. Single Gases Used For Permeation Tests

\begin{tabular}{|l|l|l|l|l|}
\hline Gas & $\begin{array}{l}\text { Molecular } \\
\text { mass } \\
(\mathrm{g} / \mathrm{mol})\end{array}$ & $\begin{array}{l}\text { Kinetic } \\
\text { diameter } \\
(\AA)\end{array}$ & $\begin{array}{l}\text { Tested } \\
\text { pressure } \\
\text { range }(\text { barg })\end{array}$ & $\begin{array}{l}\text { Tested } \\
\text { temperature } \\
\text { range }\left({ }^{0} \mathrm{C}\right)\end{array}$ \\
\hline $\mathrm{H}_{2}$ & 2 & 2.89 & $0.05-10$ & $25-450$ \\
\hline $\mathrm{He}$ & 4 & 2.6 & $0.05-10$ & $25-450$ \\
\hline $\mathrm{CH}_{4}$ & 16 & 3.82 & $0.05-10$ & $25-450$ \\
\hline $\mathrm{N}_{2}$ & 28 & 3.64 & $0.05-10$ & $25-450$ \\
\hline $\mathrm{Ar}$ & 40 & 3.7 & $0.05-10$ & $25-450$ \\
\hline $\mathrm{CO}_{2}$ & 44 & 3.3 & $0.05-10$ & $25-450$ \\
\hline
\end{tabular}

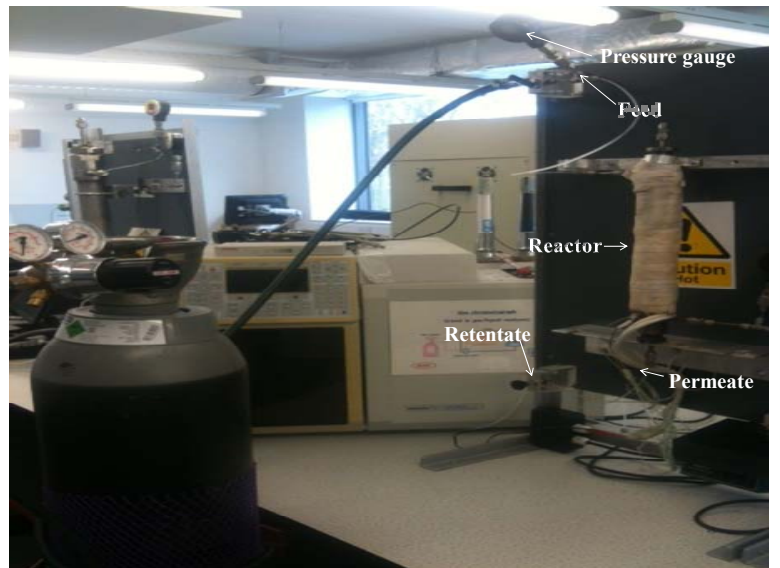

Figure 2. Pictorial View of the experimental arrangement for the membrane reactor.

\section{RESULTS AND DISCUSSION}

Different gas flow rates and feed pressure relationship was obtained from $\gamma$-alumina membrane at $165{ }^{\circ} \mathrm{C}$ (Fig. 3). This indicates a typical example of the permeation behaviour of single gases in mesoporous membranes. The pressure tested were between 0.1 to 1.0 barg and was found that the flow rate increases linearly with increasing feed pressure with good regression fits which indicates the presence of viscous flow. But $\mathrm{He}$ and $\mathrm{H}_{2}$ were kinetically activated whereas $\mathrm{CH}_{4}, \mathrm{~N}_{2}$ and $\mathrm{CO}_{2}$ followed their molecular weight parameters. Fig. 4 shows the relationship between gas permeance and molecular weight in $\gamma$-alumina membrane at $450{ }^{\circ} \mathrm{C}$. The measured permeances of the gas species $\left(\mathrm{He}, \mathrm{N}_{2}\right.$ and $\left.\mathrm{CO}_{2}\right)$ are inversely proportional to the square root of molecular weight as expressed in Eq. (4). However, (Ar and $\mathrm{CH}_{4}$ ) deviated from the linear relationship.

Fig. 5 shows $\mathrm{CO}_{2}$ flow rates and temperature relationship in $\gamma$-alumina membrane at different feed pressures. In the case of 0.05 and 0.15 barg a slight decrease of flow rate was observed between 165 to $450{ }^{\circ} \mathrm{C}$. Also, for 0.45 to 0.85 barg the flow rate is almost constant for the entire temperature increase which is in good agreement with the expected Knudsen diffusion [12]. In general, flow rate increases as the pressure increases. Gas permeance of $\left(\mathrm{N}_{2}\right.$ and $\left.\mathrm{CO}_{2}\right)$ and temperature relationship in $\gamma$-alumina membrane at 0.1 barg (Fig. 6) was almost constant due to the existance of knudsen diffusion. A slight decrease in permeance was obtained for He. 


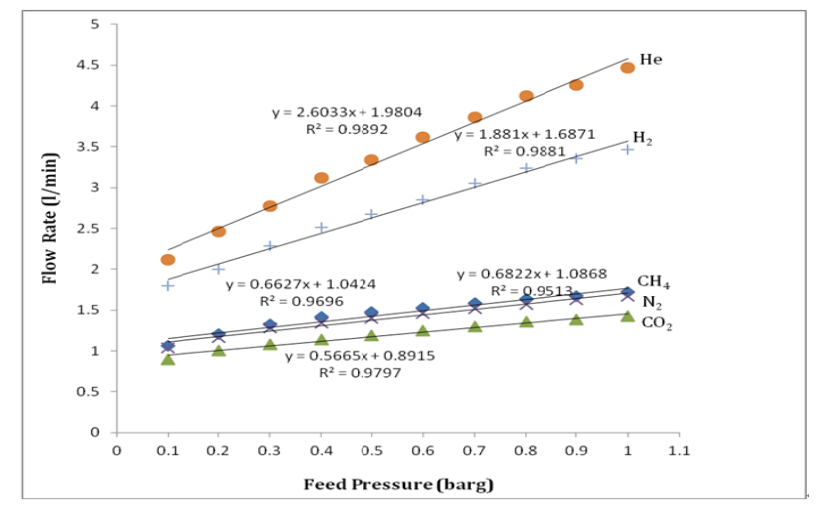

Figure 3. Different gas flow rates and feed pressure relationship in $\gamma$ alumina membrane at $165^{\circ} \mathrm{C}$.

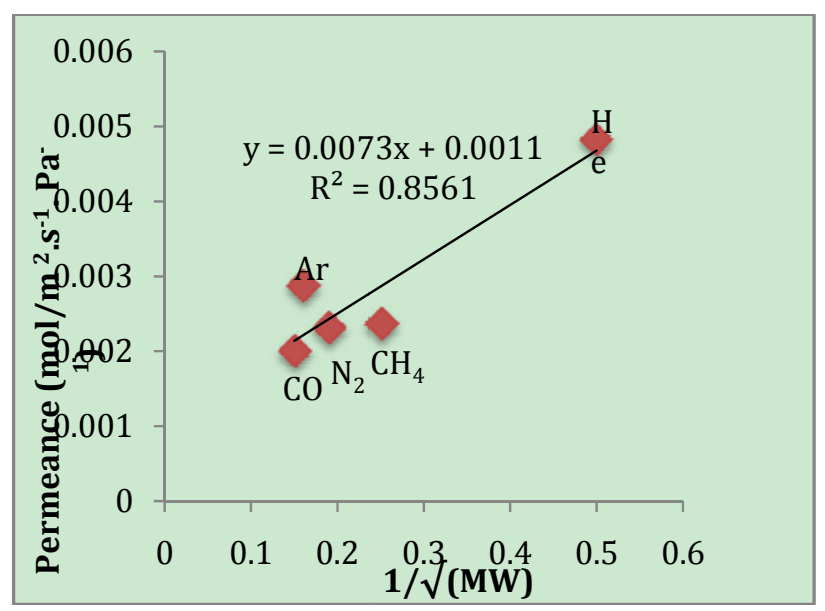

Figure 4. Different gas permeance and molecular weight relationship in $\gamma$ alumina membrane at $450{ }^{\circ} \mathrm{C}$.

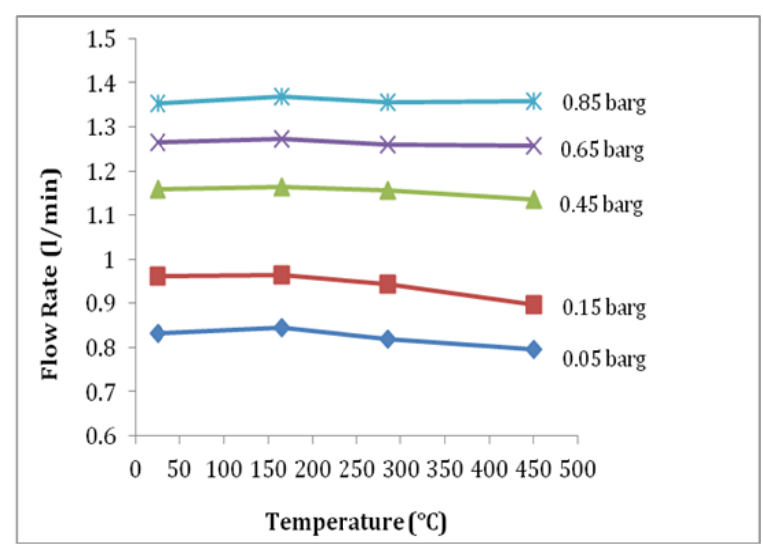

Figure 5. $\mathrm{CO}_{2}$ flow rates and temperature relationship in $\gamma$-alumina membrane at different feed pressures.

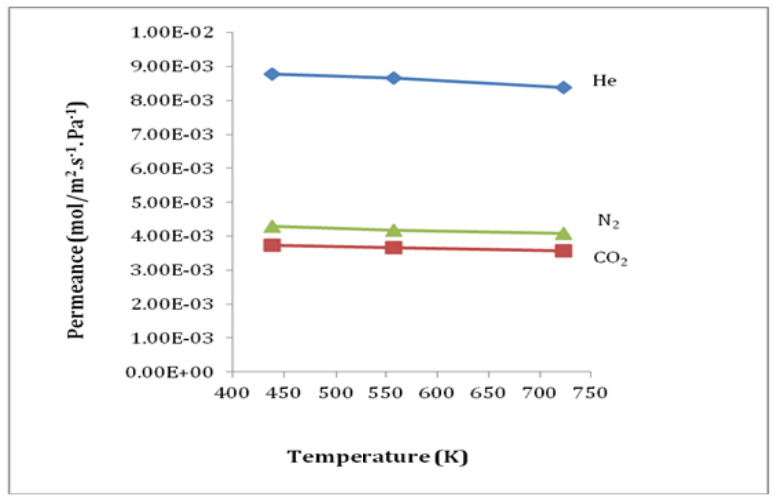

Figure 6. Different gas permeance and temperature relationship in $\gamma$ alumina membrane at 0.1 barg.

The existence of both knudsen and viscous flow mechanisms occurred at different slopes for this experiment which made it necessary to verify the correctness of Eq. (5). Wall et al [12] also verified the correctness of Eq. (5) in their work which showed a high correlation between calculated and measured data. These made us to apply feed pressures of 0.1 to 10 barg and compare our findings with their results, and our finding fits with Wall et al [12] results as shown in Fig. 7.

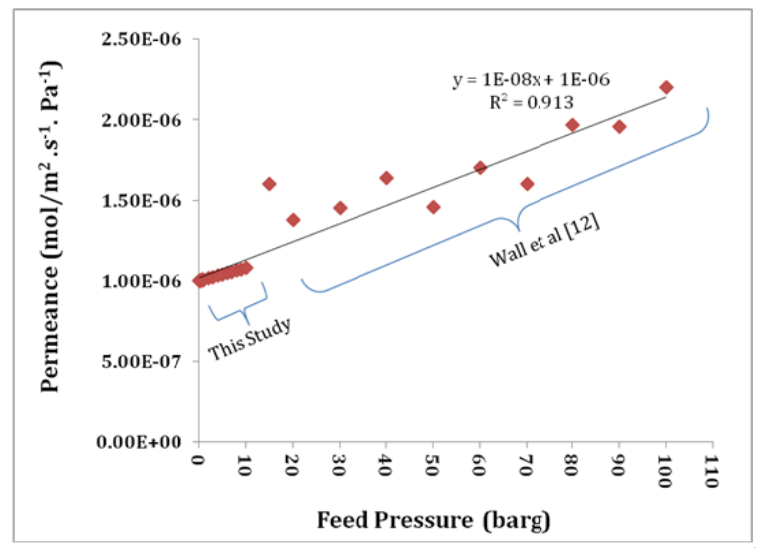

Figure 7. Permeance model of helium as a function of feed pressure at 165 ${ }^{0} \mathrm{C}$

\section{CONCLUSION}

The influence of temperature, pressure and gas molecular weight was examined from $\gamma$-alumina mesoporous ceramic membrane. In the permeation results, gas flow rates of $\left(\mathrm{He}\right.$ and $\left.\mathrm{H}_{2}\right)$ were kinetically activated whereas $\left(\mathrm{CH}_{4}, \mathrm{~N}_{2}\right.$ and $\left.\mathrm{CO}_{2}\right)$ followed their molecular weight which indicate a typical example of the permeation behaviour of single gases in mesoporous membranes due to viscous flow phenomena. Also, $\mathrm{CO}_{2}$ was tested to a temperature of up to $723 \mathrm{~K}$ and resulted with a constant flow rate for the entire pressure differences which is in good agreement with the expected Knudsen diffusion mechanism. Therefore, through the gas transport 
experiments, it can be concluded that the permeation behaviour of the tested gases in mesoporous ceramic membranes reveals the existence of both Knudsen diffusion and viscous flow mechanisms.

\section{ACKNOWLEDGEMENT}

The authors gratefully acknowledge Petroleum Technology Development Fund (PTDF) Nigeria for funding this research, and School of Pharmacy \& Life Sciences RGU Aberdeen for the SEM and EDXA results.

\section{REFERENCES}

[1] Pejman, A. N., Akbar, B. A., Elham, J., Majid, P., \& Masoumeh, A. A. An optimum routine for surface modification of ceramic supports to facilitate deposition of defect-free overlaying micro and meso (nano) porous membrane. Iran. J. Chem. Eng., 30, pp. 63-73, 2011.

[2] Shah, S. H., Uemura, Y., Yusup, S., \& Kusakabe, K. High temperature separation of hydrogen from mixture of gases by using microporous silica membranes. Journal of Materials Science and Engineering, $B(1)$, pp. 90-96, 2011

[3] Lu, G. Q., Diniz da Costa, J. C., Duke, M., Giessler, S., Socolow, R., Williams, R. H., \& Kreutz, T. Inorganic membranes for hydrogen production and purification: A critical review and perspective. Journal of Colloid and Interface Science, 314, pp. 589-603, 2007.

[4] Zhang, L., Park, I., Shqau, K., Winston Ho, W. S., \& Verweij, H. Supported inorganic membranes. Promises \& Challenges, 61, pp. 6171,2009 .
[5] Ahmad, A. L. \& Mustafa, N. N. N. Sol-gel synthesized of nanocomposite palladium-alumina ceramic membrane for $\mathrm{H}_{2}$ permeability: preparation and characterisation. International Journal of Hydrogen Energy, 32, pp. 2010-2021, 2007.

[6] Adom, P. K., Bekoe, W., Amuakwa-Mensah, F., Mensah, J. T., \& Botchway, E. Carbon dioxide emissions, economic growth, industrial structure, and technical efficiency: Empirical evidence from Ghana, Senegal, and Morocco on the causal dynamics. Energy, 47, pp. 314325, 2012.

[7] Othman, M.R., Mukhtar, H., \& Ahmad, A. L. Gas permeation characteristics across nano-Porous inorganic membranes. IIUM Engineering Journal, 5, pp. 17-33, 2004.

[8] Lee, H-J., Suda, H., \& Haraya, K. Gas permeation properties in a composite mesoporous alumina ceramic membrane. Korean J. Chem. Eng., 22, pp. 721-728, 2005.

[9] Scholes, C. A., Kentish, S. E., \& Stevens, G. W. Carbon dioxide separation through polymeric membrane systems for flue gas applications. Recent Patents on Chemical Engineering, 1, pp. 52-66, 2008.

[10] Kim, Y., Kusakabe, K., Morooka, S., \& Yang, S. Preparation of microporous silica membranes for gas separation. Korean Journal of Chemical Engineering, 18, pp. 106-112, 2001.

[11] Ohwoka, A., Ogbuke, I., \& Gobina, E. Performance of pure and mixed gas transport in reconfigured hybrid inorganic membranes part 2. Membrane Technology, pp. 7-9, 2012.

[12] Wall, Y., Ompe-Aime-Mudimu., Braun, G., \& Brunner, G. Gas transport through ceramic membranes under super-critical conditions. Desalination, 250, pp. 1056-1059, 2010. 